\title{
Mentoring siblings of gang members: A template for reaching families of gang members?
}

DOI:

10.1111/j.1099-0860.2010.00307.x

Link to publication record in Manchester Research Explorer

\section{Citation for published version (APA):}

Medina, J., Ralphs, R., \& Aldridge, J. (2012). Mentoring siblings of gang members: A template for reaching families of gang members? Children and Society, 26(1), 14-24. https://doi.org/10.1111/j.1099-0860.2010.00307.x

\section{Published in:}

Children and Society

\section{Citing this paper}

Please note that where the full-text provided on Manchester Research Explorer is the Author Accepted Manuscript or Proof version this may differ from the final Published version. If citing, it is advised that you check and use the publisher's definitive version.

\section{General rights}

Copyright and moral rights for the publications made accessible in the Research Explorer are retained by the authors and/or other copyright owners and it is a condition of accessing publications that users recognise and abide by the legal requirements associated with these rights.

\section{Takedown policy}

If you believe that this document breaches copyright please refer to the University of Manchester's Takedown Procedures [http://man.ac.uk/04Y6Bo] or contact uml.scholarlycommunications@manchester.ac.uk providing relevant details, so we can investigate your claim.

\section{OPEN ACCESS}




\title{
Mentoring Siblings of Gang Members: A Template for Reaching Families of Gang Members?
}

\author{
Juanjo Medina*, Robert Ralphs and Judith Aldridge \\ School of Law, University of Manchester, Manchester, UK
}

Mentoring has become a popular model of intervention to reduce the risk of offending, and has been proposed as an effective tool to tackle the risk of gang membership. This paper reviews the existing literature on mentoring and reports on a qualitative evaluation of a mentoring programme targeted at young people 'at risk' of gang membership in an English city. The study highlights important issues around these interventions. Although we found it a useful way to engage otherwise hard-to-reach families, important limitations remain: their potential labelling impact and their limited impact in isolation from other more ambitious measures. (c) 2010 The Author(s). Journal compilation (c) 2010 National Children's Bureau and Blackwell Publishing Limited.

Keywords: crime, early prevention, gangs, mentoring, youth justice.

\section{Introduction}

In a context where the absence of positive male role models continues to be blamed for the situation of inner city youth, mentoring remains a popular intervention. In the United States programmes like Big Brothers, Big Sisters - a Blueprint for Violence Prevention 'model programme' by the prestigious Center for Prevention and Study of Violence (University of Colorado) - is supported by more than 500 agencies, and the registry of mentoring organisation suggests that around 1700 offer mentoring schemes. Mentoring is seen as a way to promote healthy adolescent development and as a useful tool for crime reduction. Mentoring is also being integrated within broader comprehensive gang prevention initiatives (Cahill and others, 2008). In the UK the Youth Justice Board has invested heavily in mentoring. From 2001 to 2004 the Youth Justice Board spent over £10 million funding about 80 mentoring programmes. More recently, the National Association of Schoolmasters' Union of Women Teachers asked for the introduction of peer mentoring schemes involving vetted ex-gang members, a measure backed by the Youth Crime Action Plan and the Centre for Social Justice.

Despite popularity and support, academics question whether mentoring is the new 'supermarket tomato': something that can thrive under good circumstances but that, mass marketed, does not deliver quite the same quality (Durlak, 2006). In fact the literature evaluating mentoring initiatives offers a mixed picture, particularly for preventing offending (Jolliffe and Farrington, 2007).

The first meta-analysis of US programmes suggested that mentoring schemes have in general small positive effects for participating youth (DuBois and others, 2002). Most of these 55 studies used weak quasi-experimental designs and were internal evaluations. The meta- 
analysis found that mentoring had stronger effects when (1) the programme had a clear theory of change, (2) empirically based 'best practices' were used, and (3) a strong relationship was forged between youth and mentors. It also suggested that poorly implemented mentoring schemes may have adverse effects on youth. Finally, the meta-analysis seemed to suggest that mentoring was more likely to have an effect when the clients selected were youth atrisk, rather than more general populations of youth (DuBois and others, 2002).

A more recent literature review (Rhodes and DuBois, 2006) reached five main conclusions:

- Mentoring relationships are more likely to be successful when they are close, enduring and consistent.

- Programmes have achieved only limited success in establishing and sustaining such relationships.

- An inconsistent pattern of findings remains, with some programmes showing modest improvements and others failing to achieve them or even adversely affecting young people.

- We know very little as to whether mentoring is cost-effective.

- Despite these uncertainties, mentoring schemes remain a highly popular among welfare specialists, community groups and policy makers. This popularity in a context of uncertainty is leading to quality being redefined as quantity, with a growth in mentoring schemes that do not meet the criteria identified in the literature as being important in achieving success.

Two more recent meta-analyses have studied the impact of mentoring on offending. The first (Tolan and others, 2005), including results from 31 studies, found small effects on delinquency and aggression (0.24-0.28) and smaller effects on drug use (0.08) and academic success (0.16). The second considered 18 primarily American evaluations of mentoring schemes measuring the impact on crime reduction (Jolliffe and Farrington, 2007). Of these, only seven showed a positive effect, both small and short-lived. None of the more rigorous studies showed a positive impact of mentoring. These studies also suggested that:

- Those programmes that are capable of sustaining a stronger mentorship were more effective, in particular those that required weekly meetings for longer periods of time per meeting.

- Mentoring was only successful in reducing re-offending when it was part of a broader package of measures (e.g. behaviour modification, supplementary education and employment programmes).

Jolliffe and Farrington (2007) conclude that although mentoring may be promising, we still need more rigorous evaluations.

In England and Wales, the national evaluation of mentoring schemes supported by the Youth Justice Board reached rather sombre conclusions (Tarling and others, 2004). Although programme staff reported a positive outcome, the use of data contrasting experimental and comparison groups was much less conclusive. In particular, the report found that:

- Mentoring succeeded in so far as the mentees tended to reduce their truanting and school exclusion and to increase their attendance at school and their participation in community activities. However, the study could not document any changes in formally assessed 
educational achievements. This failure raised doubts as to whether the project-identified improvements were substantial enough to make a significant, lasting difference to the mentees over the long term.

- The findings available did not provide convincing evidence that mentor programmes produced a reduction in offending during the first year after the start of a programme.

- Mentor programmes proved to be more expensive than alternatives that produce similar benefits, such as the Youth Justice Board education training and employment schemes.

In the light of this, the evaluators noted that the evidence available here does not support a more widespread roll-out of mentor programmes as a means of preventing or tackling youth crime', although the findings have generated recommendations about some key features of mentoring 'which need to be preserved and combined with features of other interventions' (Professor Ian St Roberts, lead researcher, in an interview to The Guardian, 2006). Tarling and others (2004) also emphasised a model of interventions that:

- relies on professional mentors rather than amateur community volunteers;

- allows other clinicians and experts to carry out appropriate assessments of the needs of the participants;

- takes account of young people's views; and

- allows for greater joined-up intervention both horizontally, across agencies, and vertically, across age groups.

In summary, although mentoring schemes have been shown to have some success, their impact is not as strong as some assume. Also, some evaluations have documented negative effects, no effects or effects that dissipate within a few months of termination (Rhodes, 2002). When done well mentoring can have small to (more rarely) modest positive effects on some people, but we still need more research to clearly identify the characteristics of successful programmes. There are still many 'black boxes with many unanswered questions about what specific forms of interventions are effective and under which conditions' (Roberts and others, 2004, p. 512). If this is true of mentoring in general, it is even truer of mentoring oriented to prevent offending or gang membership. In relation to mentoring schemes to reduce antisocial behaviour and offending, the conclusion of St James-Roberts and others (2005) summarises the state of knowledge:

Our current state of knowledge on the effectiveness of mentoring is similar to that of a new drug that shows promise but remains in need of further research and development. There is no equivalent of the National Institute for Clinical Excellence or Food and Drug Administration for mentoring. If there were, no more than a handful of programmes might have realistic hopes of qualifying. And even then, it would have to be acknowledged that we lack full understanding of the safeguards needed to ensure that young people are not harmed by participation. For some of the most vulnerable young people, mentoring programmes as currently implemented may fail to deliver on their promises. (p. 513)

Yet, mentoring is now being deployed as a tool to deal with the new 'folk devils' encapsulating the fears of the British public: gang members. This follows the US trend to incorporate, with different degrees of success, a mentoring component within community comprehensive gang prevention schemes (Cahill and others, 2008). Here we provide feedback from one of these developing English programmes to illustrate some of the larger issues surrounding mentoring interventions with families of gang members. In particular, we highlight the problems raised by client selection, labelling and sustainability. 


\section{The programme and its evaluation}

The Gang Mentoring pilot was a short (4 months, later extended for an additional 4 months) but intensive and well resourced mentoring scheme with the goal of 'building resilience' among young people considered at elevated risk of gang membership. The mentoring scheme emerged in response to national funds made available to tackle gang issues. The programme was delivered in a large English city with a gang problem recognised from the late 1980s and a linked gun and knife violence problem that is high by British standards. For confidentiality purposes we call it Research City (for rationale, see Aldridge and Medina, 2008). These gangs emerged during the late 1980s and early 1990s in areas of Research City linked to the drug trade and suffering from high levels of social exclusion. Research City had created a multiagency forum with a 'carrots' and 'sticks' (Wyrick, 2006) approach to the prevention of gangs that matched the Eurogang definitions and were involved in firearm violence. This approach included the use of police intelligence and suppression tactics and the provision of social opportunities (e.g. housing and employment training) to gang members identified by local agencies. This forum had identified a gap in its services. It was perceived that younger siblings of identified gang members presented a higher risk for future gang involvement and that there was no mechanism to provide specific preventative services to these young children. The programme was also seen by staff as a way (1) to present local policies in a less punitive light to ameliorate strained community relations and arguably (2) to further cement the institutional presence of the local civil gang prevention team in a period when the existing funding framework for this controversial multiagency approach was coming to an end. Specialist mentoring was selected as the model of intervention given its prominence in national policy for dealing with at-risk youth. The intervention was to focus on a small group of younger siblings of gang members identified as at risk of joining gangs, and to provide them with mentor service, offer support to their families, to promote social inclusion and to raise aspirations. In particular, the intervention aimed to:

- Ensure that an identified group of younger siblings of gang members attended school on a regular basis and were therefore in a safer environment.

- Engage the group in positive activities particularly at peak times of risk in partnership with schools, and statutory and voluntary sector organisations.

- Provide information, advice and guidance to the young people, their parents and families.

The five salaried and specially trained mentors were to engage with the mentees in a number of extracurricular activities and after school activities. Normally the mentors would meet their mentees several times a week, amounting to roughly $5 \mathrm{~h}$ a week per mentee. The activities were to incorporate both play and, in theory though less often in practice, personalised learning (e.g. accessing junior youth provision, study support at school or attendance to a study centre linked to a local football club). In general, and unlike other gang prevention mentoring schemes, there was little effort on homework support and tutoring (Cahill and others, 2008) and there was a lesser focus at coordinating activities with the schools. The aims of the sessions were to build confidence and skills, as well as develop resilience. The mentors were also expected to provide support to the families, referring family members to services where appropriate.

The group of young male siblings (age 5-11) of gang members was identified by the local multiagency gang prevention team first by checking the records of a gang database constructed through police intelligence and shared by others in this multiagency forum. As we have discussed elsewhere (Ralphs and others, 2009), and others in the UK have also reported 
(Bullock and Tilley, 2008), these databases seem to rely on questionable information that is not sufficiently updated and verified and, therefore, lean towards over-identification; that is, the inclusion of false positives. The initial list of potential clients was then complemented with additional teacher-referred primary school children thought to be 'at risk' of gang membership. These referrals were then assessed by programme staff using ad hoc risk assessment criteria and, for the most part, rejected. A final list of 18 children were selected to receive the programme; with the criteria of living in areas (controversially) identified as having a gang problem (Aldridge and Medina, 2008) and gang siblings having overshadowed any other criteria for selection. It must be noted that many of the families targeted had contacted statutory agencies to get some form of intervention to address these issues. When approached by the mentoring staff they all accepted the invitation to participate, thus suggesting the possibility that the sample may have been biased towards inclusion of those who were enthusiastic and intervention-positive.

Staff from the mentoring programme approached our research team to provide some form of 'frugal' evaluation (Maxfield, 2001). As the intervention was already in place and the funding very limited, it was not feasible to obtain self-report baseline data from participating youth or to draw a comparison group. The evaluation relied primarily on in-depth, semi-structured interviews of clients, school personnel and practitioners involved in the project and the use of case studies. The assessment of the scheme relied on qualitative indicators including interviews with key personnel, systematic analysis of the case files of the mentors and the computerised data about the mentees (including the log of the mentor-mentee meetings, and feedback forms from parents and schools), and two in-depth case studies on two of the mentees and their relevant network (mentor, parent and school officials) for more in-depth, qualitative interviews.

The intervention was carried out at one of the sites where we had been conducting an ethnographic study of gangs funded by the ESRC (Economic and Social Research Council) (see Aldridge and Medina, 2008; Aldridge and others, 2010a,b; Medina and others, 2011). Some of the families and young people targeted for this intervention were already familiar to us from our ethnographic study which allowed us to further contextualise the implementation and reach of this intervention.

\section{Results}

All the schools and the parents of the children involved were asked to provide feedback about the mentoring scheme. In general, school staff had a positive view of the intervention. They thought that the programme helped to improve aspects of the children's behaviour around school attendance and punctuality, and their communication and social skills. They also remarked how the mentors had been helpful mediators between the families and the schools. This increased level of communication between parents and their children's schools was an important outcome. School staff also highlighted how the children seemed to have enjoyed the activities they engaged in and their relationships with their mentors. The project received strong school support with the general view expressed that the project could be widened to benefit a broader range of children.

Yet, apart from some marginal improvements on attendance and punctuality, the programme did not have an impact on academic performance and, in a couple of instances, was followed by a worsening of behaviour as reported by the teachers. Also, one of the schools raised problems regarding identification of appropriate children for the intervention; they 
recommended a better process of communication between school staff and the project team. This finding also highlights the need to protect mentees' confidentiality whilst ensuring that appropriate staff were aware of the scheme. To this end there was a concern that children may be singled out by staff or classmates if it became known that they were taking part in a project related to gangs. At least one of the parents recalled that a school staff member told their child: 'if you carry on like that you will end up a gang member like your brother'. The parent believed that the school staff member held a negative attitude towards their child because they were now aware an older sibling had been gang active. This finding highlights the very real danger that identifying young people as potential gang members may have long-term stigmatising effects. During our fieldwork in Research City we identified a number of instances where young people, older than those targeted by this intervention, were identified in the local gang database as 'gang associates' and excluded from schools, despite shaky evidence of gang association and clean criminal records.

On the other hand, it should be noted that a lack of knowledge on the part of schools about the background of these children may make it more difficult to develop appropriate strategies for them. A school staff member felt it was beneficial having more information about a student:

I knew he had at least three brothers, it turns out he's got six brothers. And I knew one of them had been in trouble, I didn't know what the trouble was but I knew he was in prison and I didn't know other things. I knew [sibling's name] was at [name of area] but that's all I knew. But you know, poor [mentee's name], what that child has seen and heard and its like he's very quiet and I'm not surprised he's very quiet.

This highlights the fine balance required to maintain appropriate communication channels with school staff and still ensure confidentiality in relation to the mentee's family gang links; this kind of disclosure can lead to stigmatisation and labelling.

All the feedback from the parents suggested a generally positive view of the project. The parents perceived the programme as having had a positive impact on their children. The children were said to have enjoyed the opportunities provided by the activities they engaged in. The parents perceived the intervention as positive, and welcomed it, noting the need for more activities for young people to do. They cited a lack of services in the area and noted that even if services were available, then a shortage of time and money prevented them from taking their children to them. Parents recognised the importance of keeping children occupied, and the need for their children to have hobbies and interests that may prevent them from getting involved with 'the wrong crowd' or from committing crime through boredom.

Parents also had a generally positive view of the relationships maintained with the mentors. The mentors' approachability and capacity to listen were perceived as critical. They felt that they could contact the mentors at any time and for whatever reason. All these factors combined to help establish trusting relationships. The project was perceived by the parents to have had an impact on their children's attitudes and communication, which in turn were said to have had a positive impact on family life. Some parents also talked about the way in which the mentors had enabled them to deal with problems related to their children and their own relationships with school authorities. These positive feelings about the intervention resulted in some of them expressing the desire for it to continue and wondering whether this type of intervention could have made a difference with their older children. For some 
families, having the mentor to turn to was useful in providing a mediating function allowing better communication between the parents and the school.

These results are in some ways quite extraordinary because these families all have a long record of difficult relationships with statutory agencies and a general mistrust of interventions. It was evident that the parents had experienced negative outcomes in previous interactions with services and the justice system. Often the parents we spoke with complained of the lack of support received from statutory agencies and schools in the past. In the parents' views, these agencies fail to understand the nature of their problems and only respond late and often with a disheartening 'blaming' approach of their parenting skills. Consequently it can be expected that as a result of previous negative experiences with similar statutory agencies, there will be varying degrees of mistrust towards further intervention. The following testimony from one of the mentees' parents is illustrative of this.

They told me about those parenting programmes and stuff like that. Eventually when I got help but I don't think, the problem, the issue isn't with me, I think I'm bringing him up, I brought him up to the best of my ability. The problem is what goes on out there, I can't be with him, you know, $24 \mathrm{~h}$ of the day. [...] So I said I ain't going on no parenting programme for him, for what?

In this context, programmes which focus on helping their children, rather than 'blaming them' as parents may be a way to engage with these families (Aldridge and others, 2009).

We also asked 12 of the 18 children about their experiences with the mentors. In general, the data seem to suggest that the mentors managed to develop a good relationship with them. They all felt happy with their mentors and thought that the activities they engaged in were fun and exciting. They viewed the project as giving them the chance to attend a range of primarily sporting and leisure activities that they would otherwise not be able to. They also felt that the mentors were taking their views into account when planning their joint activities. Nevertheless, some of the children seem to have desired an even closer emotional relationship. Although the programme was intensive, perhaps the short length of the scheme hampered the possibility of a closer emotional relationship.

Despite the overall positive tone of the feedback, some parents expressed concern about the future awaiting their children and the sustainability of any observed changes. A key component of the project involved after school engagement in activities. Whilst this was singled out by mentees, parents and school staff as the most positive aspect of the project, there was some difficulty in sourcing appropriate activities for this age group in Research City, particularly in the more immediate vicinity where the young people resided. Consequently, the various afterschool activities that the young people attended were spread across a wider geographical area than may have been expected. The logistics of attending these activities was overcome by the use of taxis during the project. This raises a more general problem in terms of highlighting a deficiency of appropriate activities for this age group (see also Audit Commission, 2009). The fact that mentors often had to travel several miles from the area their mentees resided means that the potential for mentees to continue attending these activities after their involvement in the project is limited. The following discussion with a mentor clearly illustrates the problems encountered in sourcing after school activities for this age group.

Interviewer: In terms of finding solutions or finding activities, did you have any difficulties there? 
Mentor: Massive, massive, massive, I really believe that children in inner Research City get a raw deal, they get such a raw deal as far as out of school activities are concerned, things to do within their community and their neighbourhoods they get a raw deal. I found out because what we had to do as mentors was to put a timetable together for them and, you know, some of it was supposed to be extended schools activities some was supposed to be free activities within the community that's affordable for the parents and honestly, even with all our resources...

Interviewer: You struggled to find activities?

Mentor: Massively, massively, massively and its really sad because these are the children I do believe need it, these are the children that need to be occupied at the weekend, need to be occupied in the evenings and there's just nothing for them.

[...]

Interviewer: What activities have you been doing with [mentee's name] after school?

Mentor: He does basketball and trampolining that was his choice but there was nothing in the area. The trampolining was done in Inner West I've got to take him all the way there to do his trampolining and I've got to take him all the way to Inner Southland to do his basketball so from that point of view can you see where the difficulties come? And then for the Mum to try and keep it up its awful.

Interviewer: Are there any kinds of financial support for them to carry on doing the activities?

Mentor: This is the thing, no there isn't because that's quite sad because I know that [mentee's parent's name] won't keep up with the activities with him on her own. Well put it this way, if he didn't get onto the programme again I don't think he would continue those activities because it's not feasible for her to do that.

Interviewer: And also just the practicalities because she's doing three jobs. [...]

Mentor: ... she's working so you can't even say she's selfish and she doesn't want to, she can't.

It is clear that the lack of affordable and accessible after-school activities available in the immediate local area will impact on the ability of parents to sustain engagement. There was a clear desire on behalf of the mentees and their parents to continue with the project and the new activities they had been involved with, yet this was accompanied by an air of resignation that in reality, once the project had ended the young people would often not continue with these activities. Although parents have been encouraged to access these activities with their children after the project ended, or to make cooperative arrangements with other mentees' parents for this to occur, this was difficult for many. Some of these families were interviewed only a few weeks after the project had ended and attendance of the activities had either stopped or reduced. It is not surprising that parents felt the project was too short.

\section{Discussion and recommendations}

Our aim was to use this evaluation as an opportunity to reflect on the broader policy drift towards using mentoring as a way to tackle gangs in Britain. The particular mentoring programme we examined succeeded in forging good relationships between the mentors and their clients. The young children and their families were very positive about the type of 
services that were provided to them. The intensive frequency of contact, the quality of the mentors employed and the approachability of the mentors all seemed to have played a role in achieving this success. Given the history of past negative experience that many of these families have had with statutory agencies and schools, this was no small achievement. In fact, a first general lesson that can be learned is that mentoring, in so far as it does not place 'blame' on the families of gang members, may be a useful approach to enlist their support for participation in other interventions.

Should we expect direct positive results of mentoring on gang membership or offending behaviour for younger siblings of gang members? Based on this intervention and our general knowledge about mentoring we are sceptical of the current British trend to strongly favour mentoring as a key tool in gang prevention. None of the children in this scheme was screened for conduct disorder and none had an offending record. Parents and school officials, for the most part, suggested an attitudinal change and marginal improvements in school readiness, although these were not translated into actual improvement in measured school performance. This finding is not too dissimilar from the findings of the second national evaluation of mentoring schemes supported by the Youth Justice Board. More worryingly, the nature of the funding that allowed this programme to be developed meant that from the outset its sustainability was in doubt. This is an unfortunate common feature of many prevention schemes (Audit Commission, 2009). The literature suggests that short mentoring schemes may end up having adverse effects on participants. The question 'What happens next?' was indeed asked by parents and officials from the schools of the mentees. There is a risk that any positive impact of the scheme on participating children may quickly dilute and that the programme may become yet another negative experience with statutory agencies for families.

In short, from what we know about mentoring, it would be reasonable to suspect that projects like these will not have a long-lasting sizable impact on offending or gang involvement. The family, individual, school or ecological risk factors for these outcomes are usually not removed by the intervention. And the direct buffering impact of mentoring is normally over once the scheme finishes. In addition, the potential buffering effect that new social bonds that may have developed as a consequence of networking and recreational activities carried out are unlikely to be maintained if families do not have the means, the time or the motivation to sustain these activities. As we encountered in this case, despite efforts at increased formal integration of preventative resources, serious problems remain in relation to access to after-school activities. As the Audit Commission (2009) recently highlighted, funding schemes that allow for sustainability and integrated approaches are critical to the prevention of antisocial behaviour. Our data further reinforce this view. This is consistent with Jolliffe and Farrington's (2007) conclusion that successful mentoring schemes are part of broader intervention packages.

A second lesson, then, is that short mentoring interventions like these on their own are unlikely to be effective tools for reducing gang activity. Unfortunately, the findings from US evaluations aimed at integrating mentoring approaches within more comprehensive and integrated strategies still show mixed results (Cahill and others, 2008), although perhaps the reason for this is that they are not being integrated with the right kinds of interventions (Gottfredson, 2001; J. Shute, unpublished data). In any case, coordinated prevention is not a panacea either. In practice it brings considerable problems of its own (Cahill and others, 2008). 
Finally, the danger and the negative consequences of labelling young people as potential gang members is very real (Ralphs and others, 2009) and it is not clear whether these interventions will address these concerns in an adequate manner. In fact, by using 'being the sibling of a gang member' or 'living in a gang area' as the key or only criterion for intervention, independent of any conduct disorder, the risk of net widening is high. In Britain, the 'gang member' concept has been operationalised by interventions in a loose way that reinforces ethnic discrimination (Ralphs and others, 2009). The broader notion of 'youth at risk of gang membership' is, therefore, an even more problematic criterion for justifying intervention.

The national evaluation of Youth Justice Board mentoring schemes emphasised the need for a model that allows clinicians and experts to carry out appropriate assessments of the needs and risk of participants. This screening is critical to the success and fairness of these interventions. The problems of net widening can be attenuated if the risk assessment for gang involvement is not disassociated from the risk assessment for offending. There are a variety of instruments employed for delinquent risk assessment of young children (such as EARL-B20), many of which are not very long or difficult to use in the context of client screening (see Howell, 2001). Given our current knowledge about risk factors for gang membership, it seems as if the more sensible approach for client selection would be to use some of these tools for client screening, with 'the presence of members in the family, as friends, as schoolmates, and in the community' as additional markers for risk (Aldridge and others, 2009). Future research should focus on assessing the usefulness and predictive accuracy of these modified instruments. This, in any case, begs the question of who screens for behavioural problems and why. Should the younger siblings of 'known'/convicted gang members be routinely screened for behavioural problems as a rationale for intervention? Or should service-providers working with children referred for serious behavioural problems prioritise support to those with 'known' gang members in the family? Information sharing between agencies would seem to be key either way but, as we illustrate, this will involve sharing of fundamentally sensitive and controversial information, particularly with regard to gang affiliation.

Thus, although it is well perceived by the parties involved and may be a useful tool to engage hard-to-reach families, the real impact and efficiency of mentoring for gang prevention has yet to be clearly documented. There are some serious concerns in relation to labelling and net widening impact (Cohen, 1985). In the light of this, it seems that great care should be taken when using mentoring, particularly in isolation from other measures, as a way of tackling the risk of gang membership. Yet, the fact that mentoring disturbs neither current political nor parental schema regarding causation and 'blame' for youth disorder/gang membership ('it's the lack of role models and positive relationships that's the problem, not entrenched social exclusion or pressurised family processes') has made it a suitable candidate for political and social support despite weak evidence to back its usefulness. Doing anything at all, even if it is tinkering around the edges, seems preferable to dealing with the issues of entrenched social exclusion that underpin the development of gangs.

\section{Acknowledgements}

We thank Julie Boyle for her capable and reliable assistance throughout this project and Jon Shute and Karen Clarke for feedback on earlier versions of this article. The research was supported by the Economic and Social Research Council (RES-000-23-0615) and by a city council (unnamed, to retain the anonymity of the location of the research). 


\section{References}

Aldridge J, Medina J. 2008. Youth Gangs in an English City: Final Report. ESRC: Swindon.

Aldridge J, Ralphs R, Medina J. 2010a. Collateral damage: gang territory and policing in an English city. Youth in Crisis? Gangs, Territoriality and Violence. Goldson B (ed). Cullompton: Willan (forthcoming).

Aldridge J, Medina J, Ralphs R. 2010b. The problem of proliferation: guidelines for improving the security of qualitative data in a digital age. Research Ethics Review 6(1): 3-9.

Aldridge J, Shute J, Ralphs R, Medina J. 2009. Blame the parents? Children and Society. D0I: 10.1111/ j.1099-0860.2009.00282.x

Audit Commission. 2009. Tired of Hanging Out. Audit Commission: London.

Bullock K, Tilley N. 2008. Understanding and tackling gang violence. Crime Prevention and Community Safety 10: 36-47.

Cahill M, Coggeshall M, Hayeslip D, Wolff D, Lagerson E, Scott M, Davies E, Roland K, Decker S. 2008. Community Collaboratives Addressing Youth Gangs. Urban Institute: Washington, DC.

Cohen S. 1985. Visions of Social Control. Polity Press: Cambridge.

DuBois D, Holloway B, Valentine J, Cooper H. 2002. Effectiveness of mentoring programs for youth. American Journal of Community Psychology 30: 157-197.

Durlak JA. 2006. Will mentoring become the next supermarket tomato? Social Policy Report 20: 12.

Gottfredson D. 2001. Schools and Delinquency. Cambridge University Press: New York.

Howell JC. 2001. Risk/needs assessment and screening devices. In Child Delinquents. Loeber R, Farrington D (eds). Sage: Thousand Oaks, CA: 395-404.

Jolliffe D, Farrington D. 2007. A Rapid Evidence Assessment of the Impact of Mentoring on Re-Offending. Home Office Online Report 11/07.

Maxfield M. 2001. Guide to Frugal Evaluation for Criminal Justice: Final Report. National Institute of Justice: Washington, DC.

Medina J, Aldridge J, Ralphs R. 2011. Gang transformation, changes or demise: evidence from an English city. Global Gangs: Comparative Perspectives. Hazen JM, Rodgers D (eds). University of Minnesota Press: Minneapolis (forthcoming).

Ralphs R, Medina J, Aldridge J. 2009. Who needs enemies with friends like these? Journal of Youth Studies 12: 483-500.

Rhodes JE. 2002. Stand By Me: The Risks and Rewards of Mentoring Today's Youth. Harvard University Press: Cambridge, Massachusetts.

Rhodes JE, DuBois D. 2006. Understanding and facilitating the youth mentoring movement. Social Policy Report 20: 3-19.

Roberts H, Liabo K, Lucas P, DuBois D, Sheldon TA. 2004. Mentoring to reduce antisocial behaviour in childhood. British Medical Journal 328: 512-514.

St James-Roberts I, Greenlaw G, Simon A, Hurry J. 2005. National Evaluation of Youth Justice Board Mentoring Schemes 2001 to 2004. Youth Justice Board: London.

Tarling R, Davison T, Clarke A. 2004. The National Evaluation of the Youth Justice Board's Mentoring Projects. Youth Justice Board: London.

Tolan P, Henry D, Shoeny M, Bass A. 2005. What We Know About What Mentoring Can and Might Do For Youth Crime. Presented at the Fifth Annual Jerry Lee Crime Prevention Symposium, May 3, Adelphi, Maryland.

Wyrick P. 2006. Gang prevention: how to make the front end of your program work. US Attorneys' Bulletin 54: 52-60.

*Correspondence to: Juanjo Medina, School of Law, University of Manchester, Williamson Bldg, Oxford Road, Manchester M139PL, UK, Tel.: 0161275 4726; Fax: 0161275 4724. E-mail: juanjo.medina@manchester.ac.uk

Accepted for publication 4 March 2010 